\title{
PADRÕES ELETROFORÉTICOS DE HORDEÍNAS E ISOENZIMAS PARA IDENTIFICAÇÃO DE CULTIVARES DE CEVADA ${ }^{1}$
}

\author{
ELISEU BINNECK ${ }^{2}$, JORGE LUIZ NEDEL ${ }^{3}$, ODIR A. DELLAGOSTIN , A.C.S.A. BARROS ${ }^{5}$ E SILMAR TEICHERT PESKE ${ }^{3}$
}

\begin{abstract}
RESUMO - O objetivo deste trabalho foi determinar os padrões de eletroforese em gel de poliacrilamida das hordeínas e isoenzimas de cinco cultivares brasileiras de cevada (Hordeum vulgare L.): Embrapa 43, Embrapa 127, Embrapa 128, Embrapa 129 e BR 2, visando a identificação das cultivares. A uniformidade (homogeneidade) desses padrões também foi determinada por meio da análise individual de 90 amostras de sementes de cada cultivar. A maioria das cultivares foi prontamente discriminada pelos eletroforegramas de hordeínas. Três cultivares apresentaram padrões únicos de hordeínas, enquanto as outras duas (Embrapa 128 e BR 2) apresentaram padrões diferentes de esterases (EC 3.1.1.1). As medidas de similaridade calculadas a partir dos dados de hordeínas e esterases conjugados, utilizando o coeficiente de Jaccard, possibilitaram discriminar todas as cultivares e biótipos encontrados. A cultivar Embrapa 43 apresentou dois biótipos bem definidos de hordeínas e esterases. A variação do perfil de hordeínas nessa cultivar foi diretamente relacionada com a variação nos zimogramas de esterase. Essa relação não foi observada em todas as cultivares que apresentaram biótipos. Pode-se constatar que a análise de dados de eletroforese de hordeínas e esterases em conjunto é um método útil para a identificação de cultivares de cevada. Termos para indexação: identificação de cultivares, PAGE, prolaminas, esterase, Hordeum vulgare.
\end{abstract}

\section{ELECTROPHORETIC PATTERNS OF HORDEINS AND ISOENZYMES FOR IDENTIFICATION OF BARLEY CULTIVARS}

\begin{abstract}
The goal of this study was to determine the polyacrylamide gel electrophoretic patterns (electrophoregrams) of the hordeínas and isozymes from five Brazilian barley cultivars: Embrapa 43, Embrapa 127, Embrapa 128, Embrapa 129 e BR 2. The uniformity (homogeneity) of these patterns also was determined through the 90 single seed samples of each cultivar. Most of the cultivars were readily discriminated by hordein electrophoregrams; five barley cultivars presented four different eletroforegrams of hordeins. Three cultivars gave unique hordein patterns, whereas the two others (Embrapa 128 e BR 2) presented different esterases (EC 3.1.1.1) patterns. Jaccard similarity measures of conjugated data of hordeínas and esterases allowed discrimination of all cultivars and biotypes. The cultivar Embrapa 43 showed two biotypes well defined of hordeins and esterases. The variation of the hodeins pattern on that cultivar have direct relation with the variation on zimograms of esterases. This relation was not found in all cultivars that presented biotypes. It was established that electrophoresis data of hordeins and esterases can be helpful on barley cultivars identification.

Index terms: cultivar identification, PAGE, prolamins, esterase, Hordeum vulgare L.
\end{abstract}

\footnotetext{
Aceito para publicação em 06.03.2002; trabalho realizado com suporte financeiro da CAPES

${ }^{2} \mathrm{Eng}^{\mathrm{o}} \mathrm{Agr}^{\mathrm{o}}$, Dr., Laboratório de Biotecnologia, Embrapa Soja, Cx. Postal 231, 86001-970, Londrina-PR; e-mail: binneck@cnpso.embrapa.br

${ }^{3}$ Prof. Titular, PhD., Depto. de Fitotecnia, FAEM/UFPel, Cx. Postal 354, Pelotas-RS; e-mail: jlnedel@ufpel.tche.br; peske@ufpel.tchel.br

${ }^{4}$ Prof. PhD. do Centro de Biotecnologia, Depto. de Botânica/UFPel; e-mail: odirad@terra.com.br

${ }^{5}$ Prof. Adjunto, Dr., Depto. de Fitotecnia, FAEM/UFPel; e-mail: acbarros@ufpel.tche.br
}

\section{INTRODUÇÃO}

A cevada (Hordeum vulgare L.) é classificada como o quarto cereal mais cultivado no mundo. A sua maior utilização é na indústria cervejeira e na alimentação animal. A correta identificação das cultivares desse cereal é de grande importância, primeiro para distinguir aquelas que apresentam qualidade de malte para a indústria cervejeira, pelo alto dife- 
rencial de preço em relação às cevadas utilizadas para a alimentação. Segundo, as diferenças no processo de malteamento para diferentes cultivares exige que os lotes sejam homogêneos e de identidade conhecida.

Os métodos tradicionalmente utilizados para identificar e avaliar a pureza de cultivares de cevada geralmente envolvem a extensa e detalhada inspeção de descritores morfológicos das plantas a campo. Esses métodos podem ser efetivos, mas dependem do dispêndio de muito tempo e espaço, considerando que grandes áreas e um longo período são necessários para cultivar as plantas até que os caracteres morfológicos e propriedades agronômicas possam ser estudados. Normalmente são medidos mais de 80 caracteres morfológicos separadamente para identificar cultivares de cevada (Lookhart \& Bean, 2000).

A discriminação de cultivares por proteínas de reserva e isoenzimas apresenta uma apreciável vantagem sobre a utilização de caracteres morfológicos da planta (Ainsworth \& Sharp, 1989), pelo fato de serem as proteínas consideradas produtos diretos da expressão gênica. Isso tem motivado a sua utilização em programas de identificação de cultivares de várias espécies (Cooke, 1995a). Para esse propósito é necessário utilizar proteínas que existam em múltiplas formas moleculares (mostrando polimorfismo) e, também, preferivelmente, que estejam presentes em grande quantidade e sejam de fácil extração (Cooke, 1994). As principais proteínas de reserva nas sementes de cevada são as prolaminas (solúveis em álcool, genericamente denominadas hordeínas em cevada) e as glutelinas (solúveis em soluções ácidas ou alcalinas) (Lookhart \& Bean, 2000), sendo que na maioria dos processos de identificação de cultivares de cevada utiliza-se a eletroforese das hordeínas (Cooke, 1995b).

No entanto, um ponto de considerável importância, aparentemente não considerado por muitos autores, é a necessidade de acessar a uniformidade (homogeneidade) do eletroforegrama de cada cultivar. Isso só pode ser conseguido pela análise individual de sementes da cultivar (Lookhart \& Wrigley, 1995; ISTA, 1992 e Cooke, 1998). Embora as cultivares atuais de cevada sejam altamente autógamas, é evidente que uma proporção delas contém biótipos (Cooke, 1984 e Stoyanova, 1996), isto é, apresentam mais de uma linha identificável eletroforeticamente. Os biótipos não são o maior obstáculo para a utilização de eletroforese para identificação de cultivares, mas eles precisam ser reconhecidos e catalogados (Cooke 1995a).

Da mesma forma que para hordeínas, os zimogramas de isoenzimas podem apresentar variações dentro da cultivar (Fedak \& Rajhathy, 1972). Essas variações constituem uma informação essencial para a utilização de tais polimorfismos em programas de identificação de cultivares e avaliação de pureza genética, evitando conclusões equivocadas. Este trabalho teve o propósito de estudar a utilização de eletroforese de proteínas e isoenzimas para a identificação das cultivares brasileiras de cevada, bem como, a avaliação da estabilidade dos eletroforegramas e zimogramas dentro de cada cultivar, identificando possíveis biótipos e estabelecendo padrões para a utilização em programas de identificação de cultivares.

\section{MATERIAIS E MÉTODOS}

Escolheram-se as cultivares de cevada Embrapa 43, Embrapa 127, Embrapa 128, Embrapa 129 e BR 2, por serem as mais cultivadas na Região Sul do Brasil. Estas foram obtidas do Serviço de Produção de Sementes Básicas (SPSB), da Embrapa - Trigo, Passo Fundo. Sementes da classe genética dessas cultivares foram produzidas em $1998 \mathrm{em}$ um ensaio regional em Pelotas, no campo experimental do Centro Agropecuário da Palma - UFPel. Foram colhidas espigas de 30 plantas típicas de cada cultivar, sendo três espigas por planta. Todas as sementes foram mantidas em câmara seca $\left(11^{\circ} \mathrm{C}\right.$ e $45 \%$ de UR) até a sua utilização. As análises do material biológico foram concluídas em até 18 meses após a colheita. A cultivar BR 2 foi selecionada para ser utilizada como padrão de referência nos géis de eletroforese.

Para a análise de hordeínas, cada semente inteira, com aproximadamente $40 \mathrm{mg}$, foi macerada e transferida para um tubo de microcentrífuga (eppendorf ${ }^{\circledR}$ ) de $1,5 \mathrm{ml}$. Nesse tubo foi adicionado $0,3 \mathrm{ml}$ da solução de extração ( $20 \%$ de 2 -cloroetanol, $0,05 \%$ de metil green e $18 \%$ de uréia, em água destilada; pH 3,2). Após agitação vigorosa, dissolvendo completamente o conteúdo da semente na solução de extração, a mistura foi mantida por uma noite em temperatura ambiente (20$22^{\circ} \mathrm{C}$ ) com os tubos fechados. Posteriormente, o conteúdo foi submetido à centrifugação a $18.000 \mathrm{x}$ g, por cinco minutos, sendo o sobrenadante utilizado para a eletroforese.

Em uma análise preliminar, constatou-se que a utilização de peróxido de hidrogênio como catalisador para iniciar a reação de polimerização do gel resultou na formação de géis com alta aderência e baixa resistência mecânica à manipulação, além de formar bandas pouco definidas e formar muito background com o coomassie blue. A utilização de persulfato de amônio em vez de peróxido de hidrogênio possibilitou a resolução desses problemas.

A mistura do gel consistiu de $10 \mathrm{~g}$ de acrilamida, $0,4 \mathrm{~g}$ de bisacrilamida, $6 \mathrm{~g}$ de uréia, $0,005 \mathrm{~g}$ de sulfato ferroso e $0,1 \mathrm{~g}$ de ácido ascórbico dissolvidos em um volume total de $100 \mathrm{ml}$ 
do tampão do gel (20ml de ácido acético glacial e $1 \mathrm{~g}$ de glicina em água destilada completando o volume de 11). A solução resultante foi colocada em refrigerador para redução da temperatura até $4^{\circ} \mathrm{C}$ e, então, foram adicionados $100 \mu \mathrm{l}$ de uma solução nova de persulfato de amônio a $10 \%$ que foi mantida sob refrigeração a $4^{\circ} \mathrm{C}$ e $300 \mu 1$ de TEMED, homogeneizando rapidamente, evitando-se a formação de bolhas de ar. Os géis foram construídos com $11 \mathrm{~cm}$ de altura, $14 \mathrm{~cm}$ de largura e $1,5 \mathrm{~mm}$ de espessura.

Observou-se a necessidade de colocar a solução no agitador magnético e, sob agitação, acrescentar os agentes polimerizantes (persulfato de amônio e TEMED). Caso contrário, a polimerização ocorre no fundo do Becker e não permite a mistura homogênea dos componentes, resultando em perda de repetibilidade nos resultados em géis diferentes. Observou-se ainda que a solução de acrilamida é estável por um mês; a acrilamida em solução, com o tempo, vai se transformando em ácido acrílico, que pode causar distorções no gel; por essa razão não é recomendável o estoque prolongado dessa solução.

O tampão do eletrodo foi preparado com $4 \mathrm{ml}$ de ácido acético glacial e $0,4 \mathrm{~g}$ de glicina, diluídos em água destilada até completar o volume de um litro. A eletroforese foi conduzida a $250 \mathrm{~V}$ (voltagem constante), até a segunda banda (púrpura) do marcador methyl green chegar ao final do gel, com o eletrodo positivo na origem (topo) do gel. A eletroforese foi realizada no interior de uma câmara refrigerada para manter a temperatura do gel, durante a corrida, entre 15 e $20^{\circ} \mathrm{C}$. Após a eletroforese, o gel foi removido das placas e colocado, por 24 horas, em bandeja de plástico contendo solução corante suficiente para cobri-lo. A solução corante foi preparada com a mistura de $10 \mathrm{ml}$ da solução CB $1 \%$ (1\% de Coomassie brilliant blue R250 em metanol) e $200 \mathrm{ml}$ da solução TCA 10\% (ácido tricloroacético a 10\%). A bandeja foi mantida coberta, sendo inicialmente submetida à agitação lenta, em shaker, por 1h30min., e depois mantida em temperatura ambiente. Após este período, o gel foi lavado com água destilada.

Para a análise das isoenzimas, as sementes foram maceradas individualmente, utilizando-se $20 \mathrm{mg}$ de cada semente para a extração. A extração foi feita em tubos de microcentrífuga, utilizando-se $100 \mu 1$ da solução formada por $0,1 \%$ de SDS em acetato de sódio $0,1 \mathrm{M}(\mathrm{pH} 8,0)$, agitando em vortex durante cinco minutos e incubando a $5^{\circ} \mathrm{C}$ durante uma noite. Após o tempo de incubação, a mistura foi centrifugada a $18000 \mathrm{x} \mathrm{g}$, a $5^{\circ} \mathrm{C}$, por $20 \mathrm{~min}$. Alternativamente, pode-se centrifugar a $2200 \mathrm{x} \mathrm{g}$, a $5^{\circ} \mathrm{C}$, por uma hora (Freeman \& Yoder, 1991).
O sistema de eletroforese utilizado para as isoenzimas foi formado pelos chamados gel empilhador e gel separador. O primeiro, possuindo $\mathrm{pH}$ 6,7 e com uma concentração de poliacrilamida de 3,3\%. O gel separador possuía $\mathrm{pH} 8,9$, sendo mais concentrado que o primeiro (7,0\% de poliacrilamida) e nele ocorreu a separação das proteínas pela eletroforese. Antes da montagem do gel, as placas foram lavadas com acetona para eliminação de qualquer resíduo de gordura. $\mathrm{O}$ gel de separação, que fica na parte inferior do sistema, foi preparado pela mistura de $4,0 \mathrm{ml}$ da solução A (Tabela 1), $8,0 \mathrm{ml}$ da solução C, 16,0ml da solução G e 4,0ml de água destilada, completando o volume de $32 \mathrm{ml}$. Após homogeneizada, essa solução foi utilizada para preencher $75 \%$ do volume $(8,25 \mathrm{~cm}$ de altura), deixando um espaço suficiente para a montagem do gel concentrador. Antes de iniciar a polimerização do gel de separação, foi vertido isobutanol saturado com Tris $1,5 \mathrm{M}$ sobre a superfície desse gel, deixando polimerizar por $30 \mathrm{~min}$. à temperatura ambiente antes de acrescentar o gel empilhador, prevenindo assim o ressecamento da superfície de transição entre os géis empilhador e separador. Após a polimerização do gel de separação, o isobutanol foi vertido e a superfície do gel lavada com água destilada, removendo o excesso de água com papel filtro. A parte superior, $25 \%$ do gel, foi então preenchida com o gel empilhador.

O gel empilhador foi preparado com $1,5 \mathrm{ml}$ da solução B (Tabela 1), 4,5ml da solução $\mathrm{D}, 1,5 \mathrm{ml}$ da solução $\mathrm{E}, 6,0 \mathrm{ml}$ da solução $\mathrm{F}$ e $15,0 \mu \mathrm{l}$ da solução de azul de bromofenol $0,1 \%$, perfazendo um volume de $13,5 \mathrm{ml}$. O gel foi utilizado $40 \mathrm{mi}-$ nutos após a sua colocação, o qual apresentava as seguintes dimensões: $11 \mathrm{~cm}$ de altura, $14 \mathrm{~cm}$ de largura e $1,5 \mathrm{~mm}$ de espessura.

O tampão do eletrodo foi preparado diluindo $200 \mathrm{ml} \mathrm{da}$ solução estoque (Tabela 1) em 1,8 litros de água bidestilada, perfazendo um volume total de 2,0 litros. Dessa solução, foi separado $600 \mathrm{ml}$ para a câmara superior e os 1,4 litros restantes foram diluídos para 4,0 litros, para a câmara inferior. Foram adicionados os tampões evitando-se a formação de bolhas. Nesse ponto, o gel estava pronto para receber a amostra. Foram utilizados $20 \mu 1$ do extrato protéico de cada semente para a análise de esterase e $15 \mu \mathrm{l}$ do extrato protéico de cada semente para os demais sistemas enzimáticos.

A eletroforese foi iniciada com $25 \mathrm{~mA}$, corrente constante, até o azul de bromofenol alcançar o gel separador. Em seguida, a eletroforese foi conduzida a $35 \mathrm{~mA}$, até o azul de bromofenol atingir o final do gel separador (cerca de três horas). Alternativamente, pode-se usar $10 \mathrm{~V} \cdot \mathrm{cm}^{-1}$ (voltagem constante). Após a eletroforese, os géis foram removidos das placas, sendo eliminado o gel empilhador, e incubados na 
TABELA 1. Preparo dos componentes do gel para separação eletroferética das isoenzimas (Soluções estoque).

\begin{tabular}{|c|c|c|}
\hline Solução & Componente & Quantidade \\
\hline A & $\begin{array}{l}\text { HCl } 1 \mathrm{~N} \\
\text { Tris } \\
\text { TEMED } \\
\text { Água } \\
\text { pH } 8,8-9,0(=8,9)\end{array}$ & $\begin{array}{l}48 \mathrm{ml} \\
36,3 \mathrm{~g} \\
0,23 \mathrm{ml} \\
\text { q.s.p100 ml }\end{array}$ \\
\hline B & $\begin{array}{l}\text { HCl } 1 \mathrm{~N} \\
\text { Tris } \\
\text { TEMED } \\
\text { Água } \\
\text { pH } 6,6-6,8(=6,7)\end{array}$ & $\begin{array}{l}48 \mathrm{ml} \\
5,98 \mathrm{~g} \\
0,46 \mathrm{ml} \\
\text { q.s.p100 ml }\end{array}$ \\
\hline C (solução estável por 1 mês) & $\begin{array}{l}\text { Acrilamida } \\
\text { Bis-acrilamida } \\
\text { água }\end{array}$ & $\begin{array}{l}28 \mathrm{~g} \\
0,735 \mathrm{~g} \\
\text { q.s.p100 ml }\end{array}$ \\
\hline D (solução estável por 1 mês) & $\begin{array}{l}\text { Acrilamida } \\
\text { Bis-acrilamida } \\
\text { água }\end{array}$ & $\begin{array}{l}10 \mathrm{~g} \\
2,5 \mathrm{~g} \\
\text { q.s.p100 ml }\end{array}$ \\
\hline $\mathrm{E}$ & $\begin{array}{l}\text { Riboflavina } \\
\text { água }\end{array}$ & $\begin{array}{l}4,0 \mathrm{mg} \\
\text { q.s.p100 ml }\end{array}$ \\
\hline $\mathrm{F}$ & $\begin{array}{l}\text { Sacarose } \\
\text { água }\end{array}$ & $\begin{array}{l}40 \mathrm{~g} \\
\text { q.s.p100 ml }\end{array}$ \\
\hline G & $\begin{array}{l}\text { Persulfato de amônio } \\
\text { água }\end{array}$ & $\begin{array}{l}0,14 \mathrm{~g} \\
\text { q.s.p100 ml }\end{array}$ \\
\hline $\begin{array}{l}\text { Tampão do eletrodo } \\
\text { (diluir 1:9 para usar) }\end{array}$ & $\begin{array}{l}\text { Tris } \\
\text { Glicina } \\
\text { água }\end{array}$ & $\begin{array}{l}3,0 \mathrm{~g} \\
14,4 \mathrm{~g} \\
\text { q.s.p } 11\end{array}$ \\
\hline Corante & $\begin{array}{l}\text { Azul de bromofenol } \\
\text { água }\end{array}$ & $\begin{array}{l}0,04 \mathrm{~g} \\
100 \mathrm{ml}\end{array}$ \\
\hline
\end{tabular}

solução apropriada para a reação de coloração das enzimas para marcar as bandas.

Esterases (EST; EC 3.1.1.1) - os géis foram incubados por uma hora no escuro com agitação lenta, à temperatura ambiente $\left(22^{\circ} \mathrm{C}\right)$, em solução formada por: $40 \mathrm{ml}$ de água destilada, $25 \mathrm{ml}$ do tampão [fosfato de potássio monobásico $0,2 \mathrm{M} \mathrm{pH} 4,3$ ], $5 \mathrm{ml}$ do tampão [fosfato de potássio dibásico $0,2 \mathrm{M} \mathrm{pH} 9,2], 50 \mathrm{mg}$ de fast blue BB salt. Essa solução foi filtrada e na mesma adicionado $1,5 \mathrm{ml}$ de alpha naphtil acetato
$1 \%$ em acetona $50 \%$ (Scandalios, 1969); fosfatases ácidas (ACP; EC 3.1.3.2) - os géis foram pré incubados em tampão acetato [acetato de sódio $0,1 \mathrm{M}$ e ácido acético $0,1 \mathrm{M}$, na proporção $1: 1(\mathrm{v} / \mathrm{v})]$ por $10 \mathrm{~min}$. Em seguida, foram imersos na solução constituída de $120 \mathrm{mg}$ de o-dianisidine tetrazotized, $120 \mathrm{mg}$ de $\alpha$-naphtil acid phophate, $150 \mathrm{ml}$ de tampão acetato por uma hora, no escuro, a temperatura ambiente com agitação lenta (AOSA, 1991); fosfogluco isomerases (PGI; EC 5.3.1.9) - os géis foram imersos numa solução contendo $75 \mathrm{mg}$ de 1 -frutose 6-fosfato, $20 \mathrm{mg}$ de NADP, 20mg de MTT, 2mg de PMS 20mg de cloreto de magnésio, $100 \mathrm{ml}$ de Tris $0,1 \mathrm{M}(\mathrm{pH} 8,0)$ e, por último, $20 \mu 1$ de glucose 6-fosfato desidrogenase. Incubouse por 50 min. no escuro, a temperatura ambiente $\left(22^{\circ} \mathrm{C}\right)$; superóxido dismutases (SOD; EC 1.15.1.1) os géis foram imersos na solução constituída de $9 \mathrm{mg}$ de riboflavina, $18 \mathrm{mg}$ de NBT, $450 \mathrm{mg}$ de fosfato de potássio monobásico, $360 \mu \mathrm{l}$ de temed e $90 \mu 1$ de água destilada, incubando no escuro por $15 \mathrm{~min}$. e depois submetidos a luz fluorescente até o aparecimento das bandas; malato desidrogenases (MDH; EC 1.1.1.37) - os géis foram incubados por $30 \mathrm{~min}$. no escuro, a temperatura de $37^{\circ} \mathrm{C}$, em uma solução contendo $4 \mathrm{ml}$ de ácido málico $0,5 \mathrm{M}$ (pH 8,0), 20mg de NAD, 20mg de MTT, $2 \mathrm{mg}$ de PMS $100 \mathrm{ml}$ de Tris $0,1 \mathrm{M}$ (pH 8,5); glutamato oxalato transaminases (GOT; EC 2.6.1.1) - os géis foram incubados durante 30 minutos, sob agitação lenta, em uma solução contendo $150 \mathrm{mg}$ de fast blue BB salt, 10mg de piridoxal 5-phosphate, 200mg de ácido aspártico, 100mg de ácido cetoglutárico, $100 \mathrm{ml}$ de tris $0,05 \mathrm{M}(\mathrm{pH} 8,0)$. O ácido aspártico foi dissolvido separadamente em $10 \mathrm{ml}$ de hidróxido de sódio $0,6 \%$.

Após a revelação os géis foram lavados com água destilada para serem fotografados.

As imagens foram capturadas e digitalizadas a partir dos géis frescos, colocados sobre uma plataforma de luz branca, utilizando o sistema Kodak EDAS 120 (Kodak Electrophoresis Documentation and Analysis System) e o programa Kodak 1D Image Analysis (Eastman Kodak Company, Rochester, USA), configurado para Coomassie Blue e exposição de 1/275 segundos. A imagens dos géis foram organizadas num sistema de base de dados e analisadas no programa Diversity Database ${ }^{\mathrm{TM}}$, versão 2.2 (Bio-Rad Laboratories). Após definidas as pistas (slots), efetuou-se a extração do background, baseado no perfil de cada pista, utilizando o método "Rolling Disk", sendo o raio do disco, em 
pixels, configurado de acordo com o tipo de dados (por exemplo, hordeínas e esterase). Esse método de extração do background é bastante robusto para clarear a discriminação entre as amostras.

As bandas foram detectadas automaticamente em cada gel. A mobilidade relativa (Rf) de cada banda foi calculada dividindo a distância que a banda migrou a partir da origem do gel pela distância entre a origem e o marcador de corrida. Sendo estabelecidos todos os tipos de bandas encontradas nas amostras, o conjunto de bandas com as respectivas mobilidades relativas foi inserido na base de dados para normalizar os perfis de bandas das diferentes amostras nos diferentes géis. A intensidade das bandas foi calculada individualmente para cada amostra (slot), utilizando uma escala comparativa baseada na densidade ótica de cada banda, em relação ao total da amostra. Esse método foi utilizado para reduzir o erro provocado pela variação na concentração de proteínas nas diferentes amostras. Foram observadas as diferenças entre os perfis de bandas encontradas entre cultivares e dentro de cada cultivar, para estabelecer a homogeneidade do(s) perfil(is) em cada cultivar.

O coeficiente de similaridade foi calculado a partir dos perfis típicos das cultivares, utilizando o coeficiente de Jaccard, construindo uma matriz de valores de similaridade, relacionando todas as cultivares duas a duas. A partir dos valores de similaridade, as cultivares foram agrupadas pelo método UPGMA (Unweighted Pair-Group Method using Aritmetic Average; média das distâncias) (Swofford \& Olsen, 1990 e Manly, 1994).

\section{RESULTADOS E DISCUSSÃO}

A Figura 1 ilustra o exemplo de um gel de eletroforese com os eletroforegramas de hordeínas das cinco cultivares de cevada. Pode-se observar que a intensidade das bandas de hordeínas em cevada é bastante estável e assim pode contribuir como dado adicional de polimorfismos na discriminação dos genótipos. A cultivar Embrapa 129 apresenta um eletroforegrama bastante distinto dos demais e pode ser separada facilmente por meio de uma análise visual. Pode-se observar também positivo). que a cultivar Embrapa 43 apresenta nitidamente dois biótipos, isto é, dois padrões de bandas. Uma análise detalhada da presença e freqüência observada dos biótipos em 90 sementes de cada um dos cultivares encontra-se na Tabela 2. Essa tabela também apresenta esquematicamente os eletroforegramas das cultivares, possibilitando a análise qualitativa (binária; 0 $\mathrm{e}+$ ) ou quantitativa $(+,++\mathrm{e}+++)$ das bandas.

Pode-se considerar que a presença de uma proteína em particular em um organismo é produto direto da expressão gênica. Portanto, amostras que apresentam a mesma banda em determinada posição no eletroforegrama possuem o mesmo alelo naquele lócus. Assim, quanto maior o número de bandas de hordeínas coincidentes, maior é a similaridade entre os genótipos (Stoyanova, 1996) e é exatamente esse princípio que foi utilizado para a construção da matriz de similaridade entre as cultivares (Tabela 3 ).

Observa-se pela Figura 2 que quase todas as cultivares estudadas foram discriminadas pelos eletroforegramas de hordeínas; cinco cultivares produziram quatro padrões diferentes. Três cultivares apresentaram eletroforegramas únicos

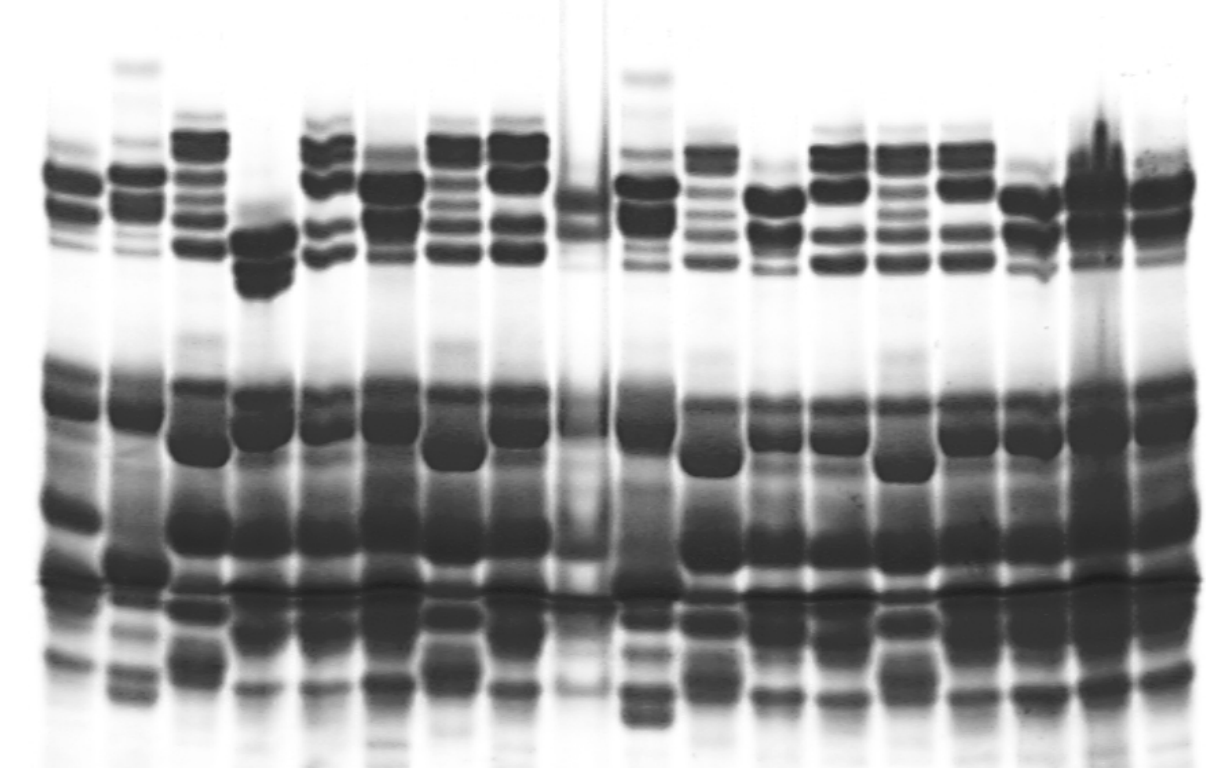

FIG. 1. Exemplo de um gel mostrando os eletroforegramas de hordeínas de cinco cultivares de cevada.

Slots (1), (9) e (18) contém o padrão, cultivar BR 2. Cada slot contém extrato protéico de uma única semente das seguintes cultivares: Embrapa 43 (2), (3), (7), (10), (11), (14); Embrapa 127 (5), (8), (13), (15); Embrapa 128 (6), (12), (16); Embrapa 129 (4); BR 2 (17). O topo da figura é a origem (pólo 
TABELA 2. Representação esquemática dos eletroforegramas das hordeínas de cinco cultivares de cevada cultivadas no Sul do Brasil.

\begin{tabular}{|c|c|c|c|c|c|c|c|c|}
\hline $\begin{array}{l}\text { Número } \\
\text { da banda }\end{array}$ & $\begin{array}{l}\text { Mobilidade relativa } \\
\text { normalizada dos } \\
\text { componentes }\end{array}$ & $\begin{array}{c}\text { Embrapa } 43 \\
(\mathrm{~A}) \\
60 \%\end{array}$ & $\begin{array}{c}\text { Embrapa } 43 \\
(\mathrm{~B})\end{array}$ & Embrapa 127 & Embrapa 128 & Embrapa 129 & BR 2 & $\begin{array}{l}\text { Número } \\
\text { da banda }\end{array}$ \\
\hline 2 & 0,33 & +++ & & +++ & tr. & & & 2 \\
\hline 3 & 0,35 & & +++ & +++ & & & $\operatorname{tr} . * *$ & 3 \\
\hline 4 & 0,37 & + & +++ & +++ & +++ & & +++ & 4 \\
\hline 6 & 0,40 & ++ & +++ & ++ & +++ & +++ & +++ & 6 \\
\hline 7 & 0,41 & & + & & + & +++ & + & 7 \\
\hline 8 & 0,44 & +++ & + & +++ & + & +++ & + & 8 \\
\hline 9 & 0,45 & & & & & ++ & & 9 \\
\hline 10 & 0,60 & ++ & ++ & ++ & ++ & ++ & ++ & 10 \\
\hline 15 & 0,85 & ++ & ++ & & & & & 15 \\
\hline 16 & 0,88 & & & +++ & +++ & ++ & +++ & 16 \\
\hline 17 & 0,90 & + & + & + & + & + & + & 17 \\
\hline 18 & 0,92 & +++ & & & & & & 18 \\
\hline 19 & 0,94 & ++ & ++ & ++ & ++ & + & ++ & 19 \\
\hline 20 & 0,96 & & ++ & & & & & 20 \\
\hline
\end{tabular}

* Proporção dos dois eletroforegramas da cultivar Embrapa 43, encontrada a partir da análise de 90 sementes.

** As bandas podem ser comparadas pela diferença qualitativa $(0 \mathrm{e}+)$ e quantitativa $(+\mathrm{a}+++)$. A abreviatura "tr." sinaliza traços.

TABELA 3. Matriz de similaridade (Jaccard) entre os eletroforegramas típicos de cinco cultivares de cevada.

\begin{tabular}{lcccccr}
\hline & Embrapa 129 & Embrapa 43B & Embrapa 43A & Embrapa 128 & Embrapa 127 & BR 2 \\
\hline Embrapa 129 & 1,000 & & & & & \\
Embrapa 43B & 0,500 & 1,000 & & & & \\
Embrapa 43A & 0,444 & 0,611 & 1,000 & & & \\
Embrapa 128 & 0,786 & 0,647 & 0,588 & 1,000 & & \\
Embrapa 127 & 0,625 & 0,611 & 0,647 & 0,688 & 1,000 & \\
BR 2 & 0,786 & 0,647 & 0,588 & 1,000 & 0,688 & 1,000 \\
\hline
\end{tabular}

de hordeínas, sendo, portanto suficiente este sistema para diferenciá-las. As cultivares Embrapa 128 e BR 2, que possuem o mesmo eletroforegrama de hordeínas, apresentaram zimogramas diferentes de esterase. Dessa forma, foi possível diferenciar todas as cinco cultivares pela análise conjunta dos dois sistemas (PAGE de hordeínas e esterase).

Apesar do grande potencial dos métodos eletroforéticos utilizando prolaminas (genericamente, hordeínas em cevada) para a discriminação e identificação de cultivares de cevada, o grau de distinguibilidade entre cultivares não é tão alto como em algumas espécies; por exemplo, o trigo. Existem algumas razões para esse fato. Entre elas podemos destacar (Cooke, 1988): (i) a cevada é uma espécie diplóide, enquanto o trigo é hexaplóide; a triplicação dos cromossomos em trigo aumenta o número de bandas de prolaminas que podem ser observadas pela eletroforese; (ii) a maioria das cultivares modernas de cevada são derivadas de poucos ancestrais e são portanto estreitamente relacionadas geneticamente; (iii) os genes que 


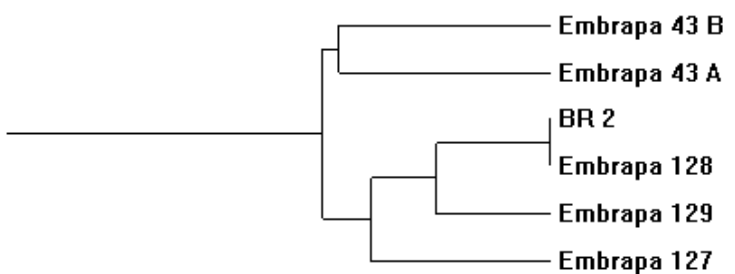

$\begin{array}{lllllllllll}0 & .1 & .2 & .3 & .4 & .5 & .6 & .7 & .8 & .9 & 1.0\end{array}$

Coeficiente de Jaccard

\section{| |||||| \\ II || I | \\ IIIII \\ IIIII \\ III I \\ | || | | |}

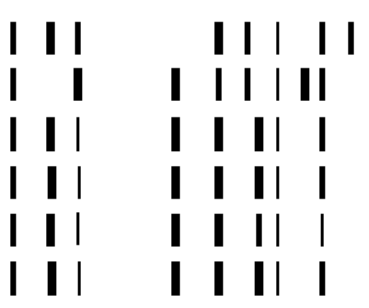

FIG. 2. Dendrograma construído pelo método UPGMA, utilizando os coeficientes de Jaccard (Tabela 3) e representação diagramática dos eletroforegramas de hordeínas de cinco cultivares de cevada.

codificam para hordeínas classificadas como B e C são localizados no mesmo braço do cromossomo 5, o que limita a probabilidade de recombinação.

Os zimogramas de esterase das cinco cultivares de cevada (Figura 3), consistiram de bandas em duas zonas distintas.

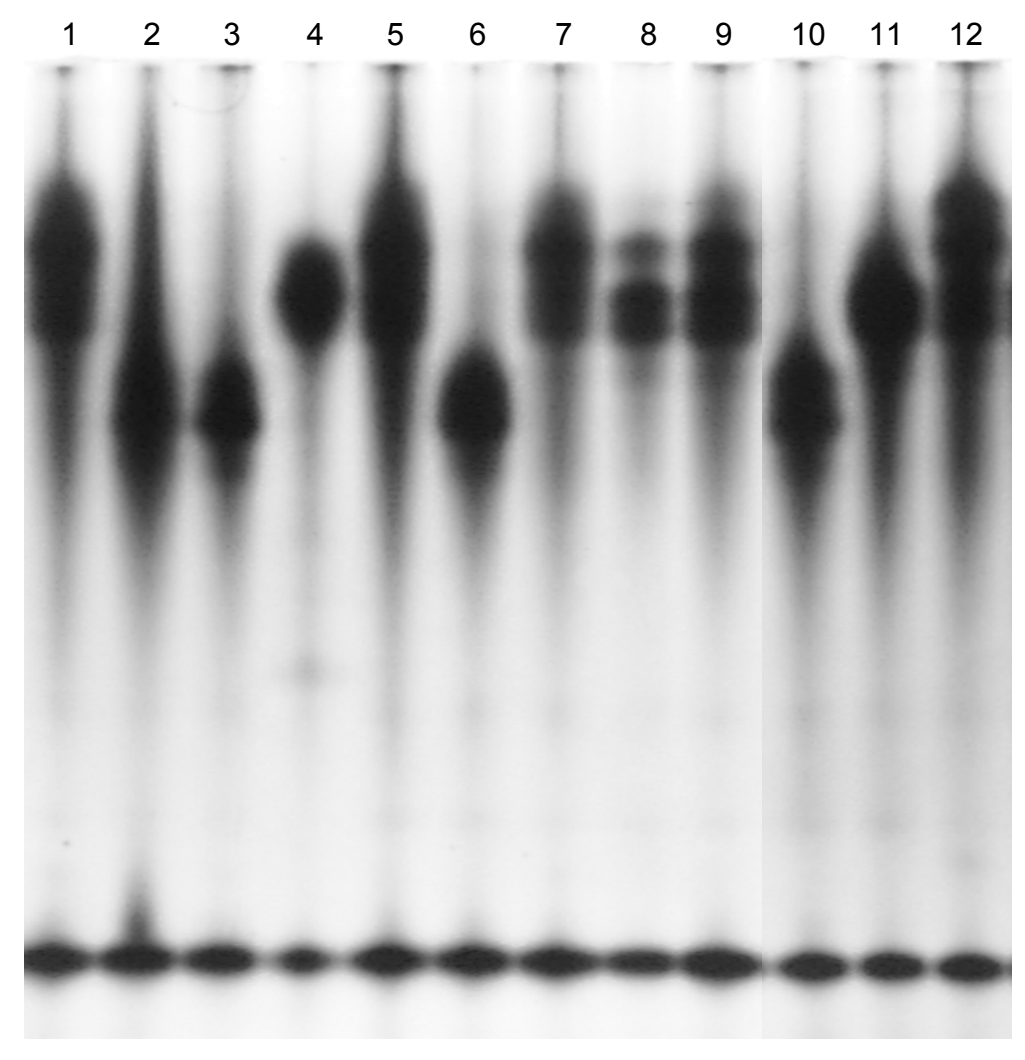

FIG. 3. Exemplo de um gel mostrando os zimogramas de esterase de cinco cultivares de cevada.

Slots (1) e (12) contém o padrão, BR 2. Slots (2) e (3) contém esterases extraídas da cultivar Embrapa 128, (4) e (5) BR 2, (6) e (7) Embrapa 129, (8) e (9) Embrapa 127 e (10) e (11) Embrapa 43
Todas as cultivares apresentaram apenas uma banda bem definida na zona inferior (banda 6), caracterizada por uma esterase de menor massa molecular. Essa zona no zimograma serve para discriminar espécies como trigo, triticale e cevada.

A zona superior dos zimogramas possibilita discriminar algumas cultivares de cevada. Por exemplo, as cultivares Embrapa 128 e BR 2, que não foram discriminadas pela análise binária dos eletroforegramas de hordeínas, podem ser discriminadas pela diferença nos padrões de esterase nessa região. Uma representação esquemática dos zimogramas de esterase das cinco cultivares de cevada é apresentada na Tabela 4. Observa-se que algumas cultivares apresentam biótipos de esterase, em freqüências diferentes. A cultivar Embrapa 43 apresentou dois biótipos de esterase, sendo esses diretamente relacionados aos biótipos de hordeínas, ou seja, as sementes que apresentaram o biótipo A e B de hordeínas apresentaram todas o biótipo A e B de esterase, respectivamente.

Apesar do grande potencial dos métodos eletroforéticos utilizando prolaminas (genericamente, hordeínas em cevada) para a discriminação e identificação de cultivares de cevada, o grau de distinguibilidade entre cultivares não é tão alto como em algumas espécies; por exemplo, o trigo. Existem algumas razões para esse fato. Entre elas podemos destacar (Cooke, 1988): (i) a cevada é uma espécie diplóide, enquanto o trigo é hexaplóide; a triplicação dos cromossomos em trigo aumenta o número de bandas de prolaminas que podem ser observadas pela eletroforese; (ii) a maioria das cultivares modernas de cevada são derivadas de poucos ancestrais e são portanto estreitamente relacionadas geneticamente; (iii) os genes que 
TABELA 4. Representação esquemática dos zimogramas de esterase de cinco cultivares de cevada cultivadas no Brasil.

\begin{tabular}{|c|c|c|c|c|c|c|c|c|c|c|}
\hline \multirow{3}{*}{$\begin{array}{l}\text { Número } \\
\text { da banda }\end{array}$} & \multirow{3}{*}{$\begin{array}{c}\text { Mobilidade relativa } \\
\text { normalizada }\end{array}$} & \multicolumn{2}{|c|}{ Embrapa 43} & \multicolumn{2}{|c|}{ Embrapa 127} & \multicolumn{2}{|c|}{ Embrapa 128} & \multicolumn{2}{|c|}{ Embrapa 129} & \multirow{2}{*}{ BR 2} \\
\hline & & $\mathrm{A}$ & B & $\mathrm{A}$ & $\mathrm{B}$ & $\mathrm{A}$ & B & $\mathrm{A}$ & B & \\
\hline & & $60 \%$ & $40 \% *$ & $90 \%$ & $10 \%$ & $97 \%$ & $3 \%$ & $54 \%$ & $46 \%$ & $100 \%$ \\
\hline 1 & 0,18 & & +++ & +++ & & & +++ & +++ & & +++ \\
\hline 2 & 0,24 & & +++ & +++ & & & +++ & +++ & & +++ \\
\hline 3 & 0,28 & & +++ & +++ & & & +++ & +++ & & +++ \\
\hline 4 & 0,36 & +++ & & & +++ & +++ & & & +++ & \\
\hline 5 & 0,41 & +++ & & & +++ & +++ & & & +++ & \\
\hline 6 & 0,94 & +++ & +++ & +++ & +++ & +++ & +++ & +++ & +++ & +++ \\
\hline
\end{tabular}

* Freqüência encontrada em 90 sementes da cultivar.

codificam para hordeínas classificadas como B e C são localizados no mesmo braço do cromossomo 5, o que limita a probabilidade de recombinação.

Os zimogramas de esterase das cinco cultivares de cevada (Figura 3), consistiram de bandas em duas zonas distintas. Todas as cultivares apresentaram apenas uma banda bem definida na zona inferior (banda 6), caracterizada por uma esterase de menor massa molecular. Essa zona no zimograma serve para discriminar espécies como trigo, triticale e cevada.

A zona superior dos zimogramas possibilita discriminar algumas cultivares de cevada. Por exemplo, as cultivares Embrapa 128 e BR 2, que não foram discriminadas pela análise binária dos eletroforegramas de hordeínas, podem ser discriminadas pela diferença nos padrões de esterase nessa região. Uma representação esquemática dos zimogramas de esterase das cinco cultivares de cevada é apresentada na Tabela 4. Observa-se que algumas cultivares apresentam biótipos de esterase, em freqüências diferentes. A cultivar Embrapa 43 apresentou dois biótipos de esterase, sendo esses diretamente relacionados aos biótipos de hordeínas, ou seja, as sementes que apresentaram o biótipo A e B de hordeínas apresentaram todas o biótipo A e B de esterase, respectivamente

Apesar do grande potencial dos métodos eletroforéticos utilizando prolaminas (genericamente, hordeínas em cevada) para a discriminação e identificação de cultivares de cevada, o grau de distinguibilidade entre cultivares não é tão alto como em algumas espécies; por exemplo, o trigo. Existem algumas razões para esse fato. Entre elas podemos destacar (Cooke, 1988): (i) a cevada é uma espécie diplóide, enquanto o trigo é hexaplóide; a triplicação dos cromossomos em trigo aumenta o número de bandas de prolaminas que podem ser observadas pela eletroforese; (ii) a maioria das cultivares modernas de cevada são derivadas de poucos ancestrais e são portanto estreitamente relacionadas geneticamente; (iii) os genes que codificam para hordeínas classificadas como B e C são localizados no mesmo braço do cromossomo 5, o que limita a probabilidade de recombinação.

Os zimogramas de esterase das cinco cultivares de cevada (Figura 3), consistiram de bandas em duas zonas distintas. Todas as cultivares apresentaram apenas uma banda bem definida na zona inferior (banda 6), caracterizada por uma esterase de menor massa molecular. Essa zona no zimograma serve para discriminar espécies como trigo, triticale e cevada.

A zona superior dos zimogramas possibilita discriminar algumas cultivares de cevada. Por exemplo, as cultivares Embrapa 128 e BR 2, que não foram discriminadas pela análise binária dos eletroforegramas de hordeínas, podem ser discriminadas pela diferença nos padrões de esterase nessa região. Uma representação esquemática dos zimogramas de esterase das cinco cultivares de cevada é apresentada na Tabela 4. Observa-se que algumas cultivares apresentam biótipos de esterase, em freqüências diferentes. A cultivar Embrapa 43 apresentou dois biótipos de esterase, sendo esses diretamente relacionados aos biótipos de hordeínas, ou seja, as sementes que apresentaram o biótipo A e B de hordeínas apresentaram todas o biótipo A e B de esterase, respectivamente

A cultivar Embrapa 129 apresenta uma variação nos zimogramas de esterase, aparentemente independente da expressão de hordeínas, resultando em dois biótipos de esterase: $54 \%$ A e $46 \%$ B. Também foram observados, em menor freqüência, biótipos secundários nas cultivares Embrapa 127 (10\% B) e Embrapa 128 (3\% B). A existência de biótipos em algumas cultivares pode ser explicada pela não existência de pressão de seleção para uniformidade de hordeínas e isoenzimas nos programas de melhoramento genético. 
Fazendo uma análise conjunta dos dados de hordeínas com os dados da zona superior dos zimogramas de esterase, foi possível discriminar exaustivamente todas as cinco cultivares de cevada (Figura 4). Na Tabela 5 encontram-se os coeficientes de similaridade, utilizados para a construção do dendrograma da Figura 4, pelo método UPGMA.

Além de esterase, foram estudados outros sistemas enzimáticos, procurando aumentar a gama de possibilidades na discriminação de cultivares de cevada. Cinco sistemas estudados Fosfatases ácidas (FAC), fosfogluco isomerases (PGI), superóxido dismutases (SOD), malato desidrogenases (MAL) e glutamato oxalato transaminases (GOT) não apresentaram polimorfismos entre as cinco cultivares estudadas (Figura 5).
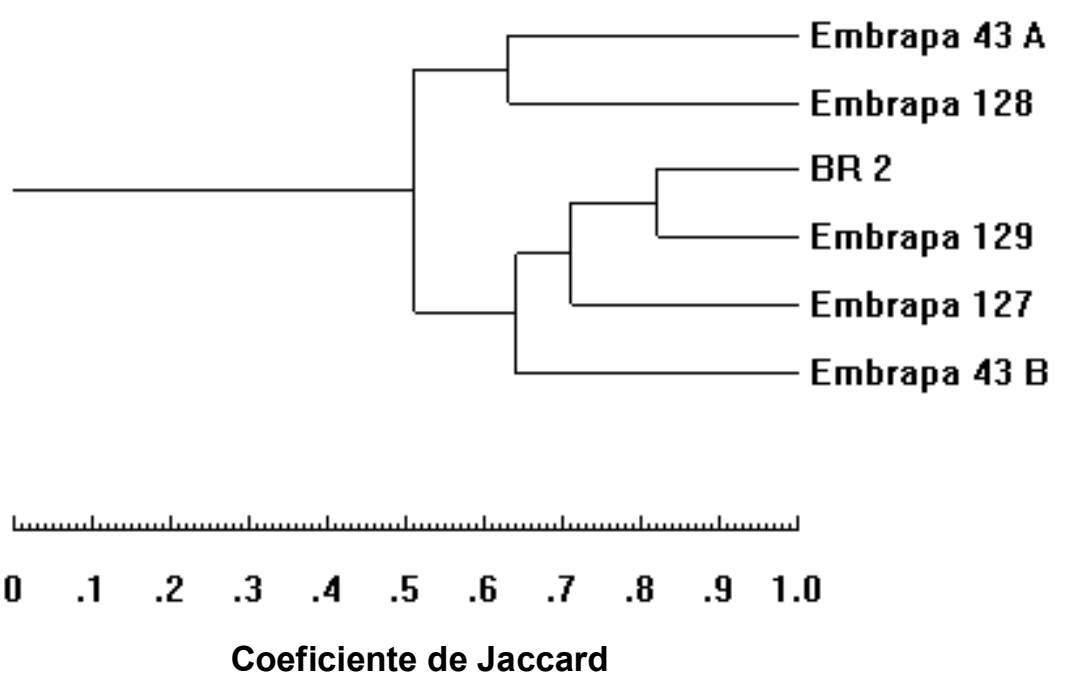

FIG. 4. Dendrograma conjugado, construído pelo método UPGMA a partir da matriz de similaridade (Tabela 5), utilizando dados conjugados de hordeínas e esterase de cinco cultivares de cevada.

TABELA 5. Matriz de similaridade (Jaccard) conjugando dados de hordénas e esterase de cinco cultivares de cevada.

\begin{tabular}{lcccccc}
\hline & Embrapa 129 & Embrapa 43B & Embrapa 43A & Embrapa 128 & Embrapa 127 & BR 2 \\
\hline Embrapa 129 & 1,000 & & & & & \\
Embrapa 43B & 0,571 & 1,000 & & & & \\
Embrapa 43A & 0,348 & 0,478 & 1,000 & & 1,000 & 1,000 \\
Embrapa 128 & 0,579 & 0,500 & 0,632 & 0,524 & 0,737 \\
Embrapa 127 & 0,684 & 0,667 & 0,500 & 0,722 & 1,000 \\
BR 2 & 0,824 & 0,700 & 0,455 & & & \\
\hline
\end{tabular}

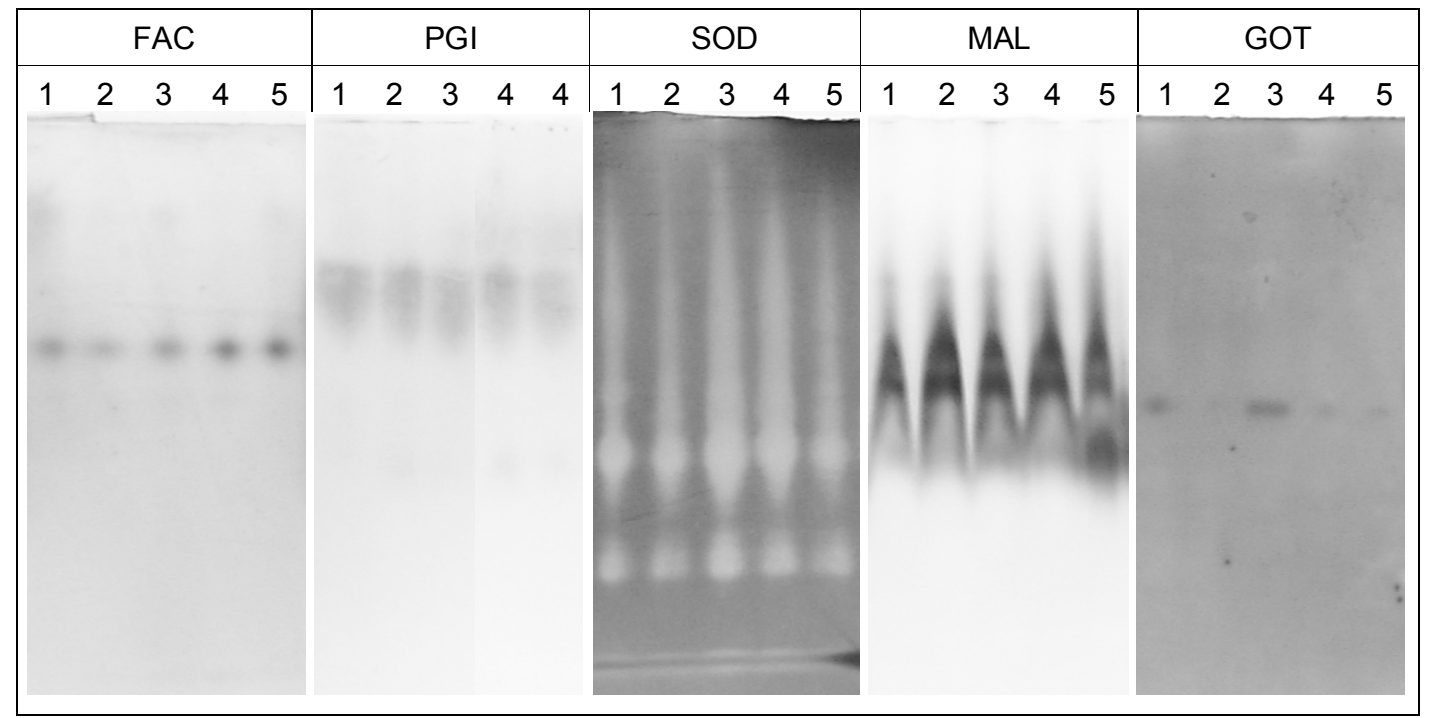

FIG. 5. Fenótipos de cinco sistemas isoenzimáticos das cultivares Embrapa 43 (1), Embrapa 127 (2), Embrapa 128 (3), Embrapa 129 (4) e BR 2 (5) de cevada.

FAC - fosfatase ácida; PGI - fosfo-gluco isomerase; SOD - superóxido dismutases; MAL - malato desidrogenase; GOT glutamato oxalato transaminase). 


\section{CONCLUSÕES}

- A análise de dados de eletroforese de hordeínas e esterases em conjunto é um método útil para a identificação de cultivares de cevada;

- a cultivar Embrapa 43 de cevada apresenta dois biótipos bem definidos de hordeínas e esterases. A variação do perfil de hordeínas nessa cultivar é diretamente relacionada com a variação nos zimogramas de esterase. Essa relação não é observada em todas as cultivares de cevada que apresentam biótipos.

\section{AGRADECIMENTOS}

Os autores agradecem à assistência técnica de Maria Alice Castro.

\section{REFERÊNCIAS}

AINSWORTH, C.C. \& SHARP, P.J. The potential role of DNA probes in plant variety identification. Plant Varieties and Seeds, Cambridge, v.2, n.1, p.27-34, 1989.

AOSA - ASSOCIATION OF OFFICIAL SEED ANALYSTS. Cultivar purity testing handbook. Lincoln, 1991. 78p.

COOKE, R.J. The characterization and identification of crop cultivars by electrophoresis. Electrophoresis, Weinheim, v.5, n.1, p.59$73,1984$.

COOKE, R.J. Electrophoresis in plant testing and breeding. Advances in Electrophoresis, Landshut, v.2, n.2, p.171-261, 1988.

COOKE, R.J. Variety identification: Modern techniques and applications. In: BASRA, A.S. (ed.). Seed quality: basic mechanisms and agricultural implications. Binghamton: Food Products Press, 1994. p.279-318.
COOKE, R.J. Gel electrophoresis for the identification of plant varieties. Journal of Chromatography, Amsterdam, v.698, n.1-2, p.281-299, 1995a.

COOKE, R.J. Identification of barley varieties. In: WRIGLEY, C.W. (ed.). Identification of food-grain varieties. St.Paul: American Association of Cereal Chemists, 1995b. p.221-237.

COOKE, R.J. The use of electrophoresis for variety identification. In: ISTA VARIETY TESTING WORKSHOP, Pretoria, 1998. Anais. Pretoria: ISTA, 1998. 25p.

FEDAK, G. \& RAJHATHY, T. Esterase isozymes in Canada barley cultivars. Canadian Journal of Plant Science, Ottawa, v.52, n.4, p.507-516, 1972.

FREEMAN, G.W. \& YODER, F.A.JR. Examination of Kentucky bluegrass blends using esterase isoenzime electrophoresis. Seed Science and Technology, Zürich, v.19, n.2, p.553-560, 1991.

ISTA - INTERNATIONAL SEED TESTING ASSOCIATION. Electrophoresis handbook: variety identification. In: ISTA handbook of variety testing. Zürich, 1992. 50p.

LOOKHART, G. \& BEAN, S. Cereal proteins: composition of their major fractions and methods for identification. In: KULP, K. \& PONTE, J.G. (eds.). Handbook of cereal science and technology. New York: Marcel Dekker, 2000. p.363-383.

LOOKHART, G.L. \& WRIGLEY, C.W. Variety identification by electrophoretic analysis. In: WRIGLEY, C.W. (ed.) Identification of food-grain varieties. St.Paul: American Association of Cereal Chemists, 1995. p.55-71.

MANLY, B.F.J. Multivariate statistical methods: a primer. London: Chapman \& Hall, 1994. 215p.

SCANDALIOS, J.G. Genetic control of multiple molecular forms of enzymes in plants: a review. Biochemical Genetics, New York, v.3, n.3, p.37-79, 1969.

STOYANOVA, S.D. Variation of gliadins in wheat cultivars associated with seed survival and multiplication. Seed Science and Technology, Zürich, v.24, n.2, p.115-126, 1996.

SWOFFORD, D.L. \& OLSEN, G.J. Phylogeny reconstruction. In: HILLIS, D.M. \& MORITZ, C. (eds.). Molecular systematics. Sunderland: Sinauer Associates, 1990. p.411-501.

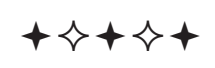

